\title{
Different graft thicknesses after Descemet stripping endothelial keratoplasty for bullous keratopathy in the two eyes of the same patient
}

This article was published in the following Dove Medical Press journal: International Medical Case Reports Journal

\section{Leopoldo Spadea \\ Emanuele Tonti \\ Rita Napolitano}

Eye Clinic, Department Sensory Organs, Policlinico "Umberto I", "Sapienza" University of Rome, Rome, Italy
Correspondence: Leopoldo Spadea Eye Clinic, Policlinico Umberto I,

"Sapienza" University of Rome, Via Benozzo Gozzoli 34, 00142 Rome, Italy Tel +39065193220

Fax +3906 88657818

Email leopoldo.spadea@uniromal.it
Objective: To describe a very unique case of two Descemet stripping automated endothelial keratoplasty (DSAEK) surgeries performed in both eyes of the same patient with an extremely different graft thickness and overall corneal thickness but with the same corrected distance visual acuity (CDVA) 2 years after surgery.

Case presentation: A 75-year-old woman with bilateral bullous keratopathy (BK) was submitted to DSAEK surgeries in both eyes, first in right and after 6 months in left eye. CDVA was 20/160 in the right eye and 20/63 in the left eye. Corneal thickness evaluated by anterior segment optical coherence tomography was $569 \mu \mathrm{m}$ in the right eye and $560 \mu \mathrm{m}$ in the left eye. The root mean square (RMS) was 2.1 in the right and left eyes. Endothelial cell densities were not detectable in both eyes. The estimated precut donor graft thickness from eye bank was 250 and $40 \mu \mathrm{m}$ in the right and in the left graft, respectively. Two years after surgery CDVA was $20 / 25$ in both eyes. Corneal thickness was $633 \mu \mathrm{m}$ with a lenticule thickness of $206 \mu \mathrm{m}$ in the right eye and $439 \mu \mathrm{m}$ with a lenticule thickness of $48 \mu \mathrm{m}$ in the left eye. The RMS was 1.7 in the right eye and 1.4 in the left eye. Endothelial cell density was 2.272 cells $/ \mathrm{mm}^{2}$ in the right and 2.154 cells $/ \mathrm{mm}^{2}$ in the left eye.

Conclusion: DSAEK was safe and effective in the treatment of BK. In our report, the visual outcome resulted to be poorly related either to donor graft thickness or to postoperative corneal thickness.

Keywords: anterior segment OCT, bullous keratopathy, Descemet stripping endothelial keratoplasty, graft thickness, visual acuity

\section{Introduction}

Descemet stripping automated endothelial keratoplasty (DSAEK) is a relatively novel surgical technique that replaces the corneal endothelium in patients with endothelial disease of various origins, with several advantages if compared with standard penetrating keratoplasty (PKP). ${ }^{1}$

In the past years, efforts were made to develop newer strategies to implant thinner graft (ultrathin DSAEK) ${ }^{2}$ up to Descemet's membrane endothelial keratoplasty (DMEK), in order to improve the final visual outcome. Thinner grafts have been correlated with a faster visual rehabilitation at the cost of more complications, such as primary graft dislocation; ${ }^{2}$ therefore, nowadays it is not clear which endothelial keratoplasty technique is the best choice for the patient. ${ }^{3}$ Our report describes a case of two DSAEK surgeries performed in both eyes of the same patient with extremely different graft thickness and postoperative overall corneal thickness but the same final corrected distance visual acuity (CDVA). 


\section{Case report}

A 75-year-old woman with bilateral Fuchs dystrophy developed bullous keratopathy after cataract surgery in both eyes and evidenced a diffuse and visually significant corneal edema, with no related ocular diseases. CDVA was 20/160 in the right eye $\left(-1.50=-0.75 \times 90^{\circ}\right)$ and $20 / 63$ in the left eye $\left(-2.50=-1.25 \times 90^{\circ}\right)$. Corneal thickness was assessed by anterior segment optical coherence tomography (AS-OCT) (RTVue OCT Optovue Inc., Fremont, CA, USA), and it was $569 \mu \mathrm{m}$ in the right eye and $560 \mu \mathrm{m}$ in the left eye. The analysis of anterior corneal surface maps was performed by videokera- tography (Oculus Optikgeräte GmbH, Wetzlar, Germany). Total higher-order aberrations (HOAs) and root mean square (RMS) from the third to eighth order were evaluated. The RMS was 2.1 in the right and in the left eye (Figure 1A, B). Corneal endothelial pattern and cell density were measured by non-contact specular microscopy (Tomey EM-3000, Tomey Co., Japan); endothelial cell densities were not detectable in both eyes because of bilateral total corneal decompensation.

Patient received a comprehensive eye examination before each surgery and at 1, 6, 12, and 24 months after each DSAEK (Table 1).
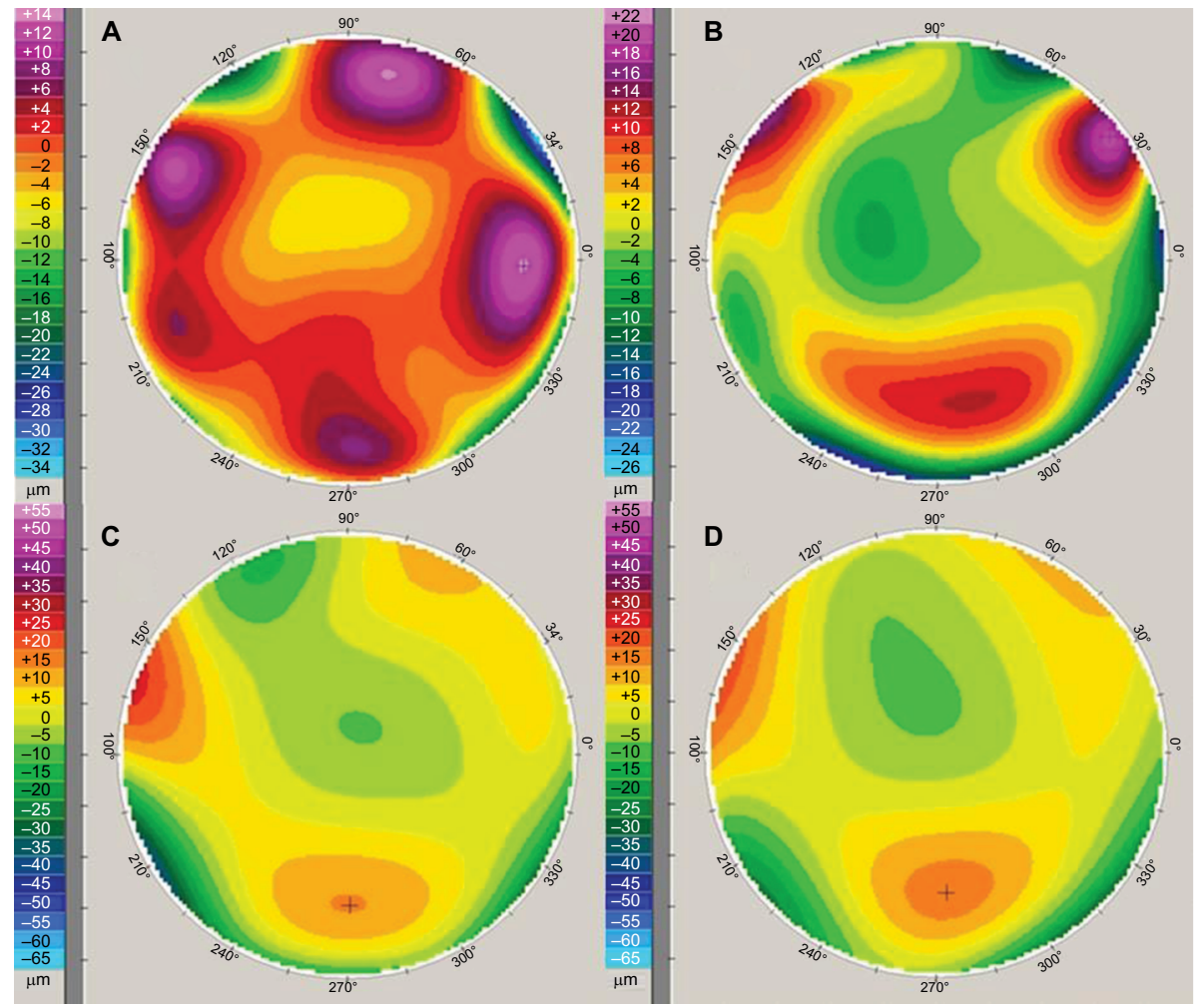

Figure I Preoperative corneal anterior surface wavefront error, RMS map (over a $6 \mathrm{~mm}$ diameter optical zone), right eye (A) and left eye (B). The RMS value was 2.1 in both eyes. After 24 months from the Descemet stripping automated endothelial keratoplasty, right eye (C) and left eye (D); the RMS value was, respectively, I.7 in and I.4. Note: The patterns showed a slight improvement in corneal profile with a mild reduction of higher-order aberrations.

Abbreviation: RMS, root mean square.

Table I Results of eye examination before surgery and after Descemet stripping automated endothelial keratoplasty

\begin{tabular}{|c|c|c|c|c|c|c|c|c|c|c|}
\hline \multirow[t]{2}{*}{ Time } & \multicolumn{2}{|c|}{ CDVA (Snellen) } & \multicolumn{2}{|c|}{$\begin{array}{l}\text { Corneal thickness } \\
(\mu \mathrm{m})\end{array}$} & \multicolumn{2}{|c|}{$\begin{array}{l}\text { Graft thickness } \\
(\mu \mathrm{m})\end{array}$} & \multicolumn{2}{|c|}{ RMS } & \multicolumn{2}{|c|}{$\begin{array}{l}\text { Endothelial } \\
\text { count (cells/ } \\
\mathbf{m m}^{2} \text { ) }\end{array}$} \\
\hline & RE & LE & RE & LE & RE & LE & RE & LE & RE & LE \\
\hline Before surgery & $20 / 160$ & $20 / 63$ & 569 & 560 & NA & NA & 2.1 & 2.1 & NA & NA \\
\hline I month & $20 / 50$ & $20 / 60$ & 706 & 489 & 254 & 50 & 2.0 & 1.9 & 2.315 & 2.256 \\
\hline 6 months & $20 / 30$ & $20 / 25$ & 685 & 456 & 239 & 55 & 1.7 & 1.6 & 2.302 & 2.226 \\
\hline 12 months & $20 / 25$ & $20 / 25$ & 676 & 450 & 230 & 53 & 1.7 & 1.4 & 2.296 & 2.180 \\
\hline 24 months & $20 / 25$ & $20 / 25$ & 633 & 439 & 206 & 48 & 1.7 & 1.4 & 2.272 & 2.154 \\
\hline
\end{tabular}

Abbreviations: CDVA, corrected distance visual acuity; LE, left eye; NA, not available; RE, right eye; RMS, root mean square from the third to eigth higher-order aberrations. 
One experienced surgeon performed DSAEK surgeries in both eyes, first in the right and after 6 months in the left eye. A temporal $4.5 \mathrm{~mm}$ clear cornea incision was made after administering peribulbar anesthesia and two paracenteses were made inferiorly and nasally. An anterior chamber maintenance cannula was introduced through the inferior paracentesis. Descemet stripping was carried out for a diameter of $8.0 \mathrm{~mm}$ using a reverse-bent Sinskey hook (ASICO, Westmont, IL, USA). Precut donor graft from eye bank (San Giovanni Eye bank of Rome, Italy), prepared using the conventional DSAEK technique of a single microkeratome pass, was trephined at a size of $8.0 \mathrm{~mm}$. A Busin glide (Moria, Antony, France) was charged with the donor graft and a microincision forceps was introduced into nasal side entrance and passed through the anterior chamber to grab the graft and drag it into the eye. The air was carefully introduced into the anterior chamber to expand the graft. Twenty minutes after the injection of air, most of the air was substituted with a balanced salt solution.

Postoperative therapy for the first two weeks was $0.3 \%$ drops of tobramycin, $0.1 \%$ drops of dexamethasone, and $0.1 \%$ drops of sodium diclofenac 3 times a day.

The $0.1 \%$ clobetasone butyrate drops were administered 3 times a day for the following 3 months, then gradually reduced and discontinued.

No significative intraoperative and postoperative complications were evidenced. Both grafts were attached and cleared up during the first 7 days. The grafts resulted of uniform thickness with no clinically significant interface haze (Figure 2A, B).
After 2 years, the CDVA was 20/25 in both eyes (right eye $-0.50=-1.25 \times 170^{\circ}$; left eye $-0.50=-1.00 \times 10^{\circ}$ ). Corneal thickness detected with AS-OCT was $633 \mu \mathrm{m}$, with a lenticule thickness of 206 and $439 \mu \mathrm{m}$, with a lenticule thickness of $48 \mu \mathrm{m}$, respectively, in the right and in the left eye (Figure $2 \mathrm{C}, \mathrm{D})$. Then, both grafts were different in thickness from the very beginning and did not suffer many changes during the follow-up period. The RMS was 1.7 in the right eye and 1.4 in the left eye (Figure 1C, D). Endothelial cell density was 2.272 cells $/ \mathrm{mm}^{2}$ in the right and 2.154 cells $/ \mathrm{mm}^{2}$ in the left eye.

\section{Informed consent}

Written informed consent has been provided by the patient for the publication of her case details and images.

Institutional review board approval was not required as patient was treated with approved diagnostic and therapeutic procedures according to generally accepted standards of care.

\section{Discussion}

DSAEK is a relatively novel development in corneal transplantation that replaced standard PKP in the management of endothelial dysfunctions. ${ }^{4,5}$ Visual outcomes are good in most cases after DSAEK, but the percentage of patients achieving a 20/20 CDVA vision is not as high as it could be supposed, despite the apparently clear postoperative graft, and the reasons for this suboptimal visual outcome are still unclear. ${ }^{3}$ Differences in the age of patients, stage, and in the duration of the disease at the time of surgery, the character-

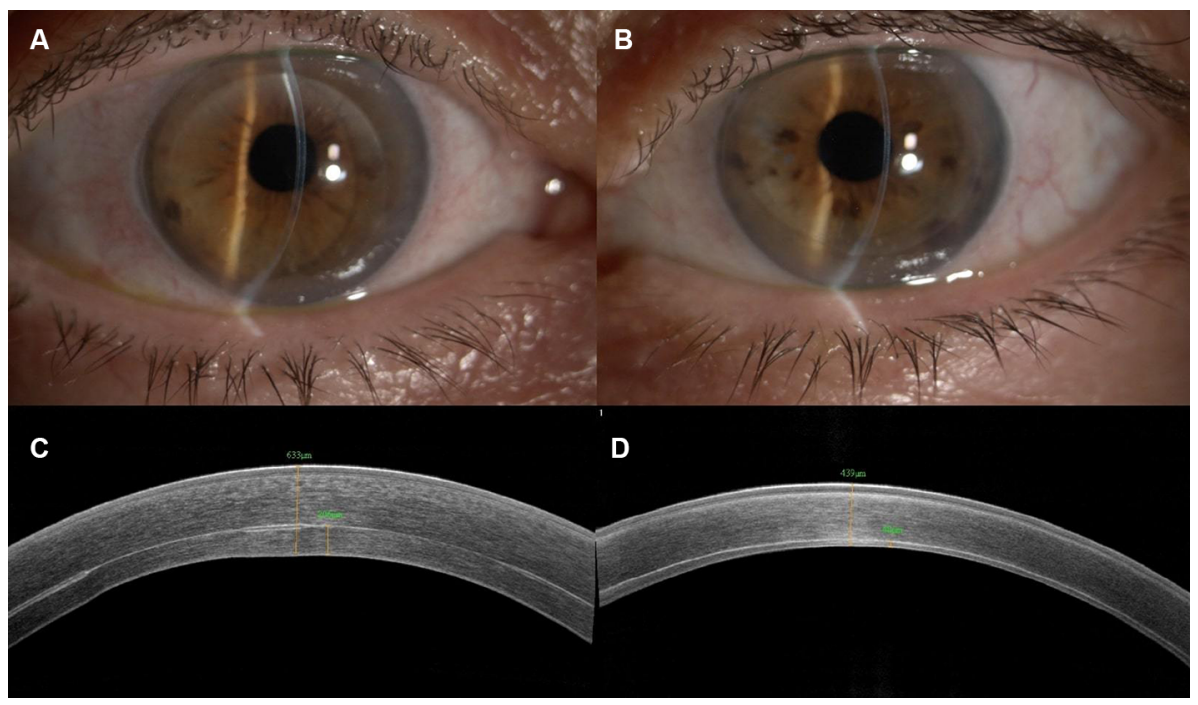

Figure 2 Biomicroscopic image of the patient's eye after 24 months from Descemet stripping automated endothelial keratoplasty surgery (A, right eye; B, left eye). Both corneas are clear assessing the success of the transplant. Anterior segment optical coherence tomography images of right eye (C) and left eye (D) evidenced the different corneal thickness between the two eyes, 24 months post surgery. 
istics of graft-host interface, the anterior stromal changes, the induced high-order aberrations, and the different graft thickness have been indicated as possible causes. ${ }^{6}$

Various studies have been published with contradictory evidence about the relationship between graft thickness and final CDVA. According to Phillips et al, ${ }^{7}$ graft thickness measurements were not correlated with the CDVA after the DSAEK with visual acuity evaluated at $1,6,12$, or 24 months postoperatively. Terry et $\mathrm{al}^{8}$ in their retrospective-designed study have concluded that preoperative graft thickness may have a small effect on visual outcome in the extremes of thickness but not in the common range of 100-200 $\mu \mathrm{m}$. In a recent meta-analysis, Wacker et $\mathrm{al}^{9}$ have found insufficient evidence that graft thickness is clinically important with respect to CDVA after DSAEK, and then graft thickness should not be important for surgical planning. On the contrary, other authors found that thin grafts after DSAEK ensure a better visual rehabilitation, such as Acar et $\mathrm{al}^{10}$ and Busin and Albe. ${ }^{2}$

Although there is discordant evidence regarding the final visual outcome, in the last years, efforts have been made to develop newer surgical techniques to implant thinner graft. ${ }^{2}$

Nevertheless, according to a recent meta-analysis there is low evidence that DMEK is better than DSAEK in terms of final CDVA, and the difference is equivalent to reading one or two lines more on a vision chart. ${ }^{3}$

Authors have emphasized the role of anterior surface in DSAEK: the condition of the recipient cornea, especially the regularity of the anterior surface, may indeed play an important role in determining the visual outcome regardless of graft thickness. HOAs from the anterior corneal surface are higher in the eyes necessitating DSAEK for bullous keratopathy than the corresponding age controls and remain higher for 1 year after DSAEK. ${ }^{11}$ Long-lasting corneal edema and irregularity of the anterior refractive surface may lead to changes in the anterior stroma that may hinder visual acuity after DSAEK. ${ }^{12}$ The lower would be the distance from the ideal plane of various parts of the same surface considered, the more regular would be the corneal shape at all levels (anterior, interface, and posterior surface) and this is related to lower ocular aberrations. ${ }^{13}$ Even though being a single case, in our report a substantial correlation from preoperative corneal thickness with preoperative and postoperative HOAs and CDVA was not shown.

Dickman et al hypothesized that not only the single value of graft thickness but also the regularity of donor tissue in the optically relevant $6 \mathrm{~mm}$ central zone, as evaluated by Scheimpflug technology, is significant for the visual outcome. ${ }^{14}$ Graffi et al found that the regularity of the interface and posterior corneal surface is better in DSAEK grafts below $100 \mu \mathrm{m}$ of thickness. According to the same authors, in eyes with Fuchs endothelial dystrophy that are otherwise healthy, thinner grafts yield significantly better CDVA, thus confirming the previous observation by Dickman et al. ${ }^{13}$

\section{Conclusion}

Although the contrasting evidence that graft thickness is related to a better CDVA after DSAEK, several findings of various authors suggest a weak relationship. Our report describes an extreme difference of postoperative graft and corneal thickness with comparable HOAs in the two eyes of the same patient, which leads to the same final visual acuity although the precut DSAEK grafts, received from the eye bank, were prepared with the same standard technique, leading to an unplanned different thickness of the two grafts. Well-designed longitudinal studies with standardized measurements of visual acuity and graft thickness are necessary to better clarify the relationship between graft thickness and visual acuity after DSAEK surgery.

\section{Disclosure}

The authors report no conflicts of interest in this work.

\section{References}

1. Eye bank Association of America. 2008. Eye Banking Statistical Report. Washington, DC: Eye bank Association of America; 2009:1-17.

2. Busin M, Albé E. Does thickness matter: ultrathin Descemet stripping automated endothelial keratoplasty. Curr Opin Ophthalmol. 2014;25(4):312-318.

3. Stuart AJ, Romano V, Virgili G, Shortt AJ. Descemet's membrane endothelial keratoplasty (DMEK) versus Descemet's stripping automated endothelial keratoplasty (DSAEK) for corneal endothelial failure. Cochrane Database Syst Rev. 2018; 6:CD012097.

4. Liu S, Veldman P. Evidence-based endothelial rehabilitation. Semin Ophthalmol. 2017;32(1):96-103.

5. Spadea L, Cifariello F, Bianco G, Balestrazzi E. Long-term results of penetrating keratoplasty using a single or double running suture technique. Graefes Arch Clin Exp Ophthalmol. 2002;240(5):415-419.

6. Mencucci R, Favuzza E, Tartaro R, Busin M, Virgili G. Descemet stripping automated endothelial keratoplasty in Fuchs' corneal endothelial dystrophy: anterior segment optical coherence tomography and in vivo confocal microscopy analysis. BMC Ophthalmol. 2015;15(1):99.

7. Phillips PM, Phillips LJ, Maloney CM. Preoperative graft thickness measurements do not influence final BSCVA or speed of vision recovery after Descemet stripping automated endothelial keratoplasty. Cornea. 2013;32(11):1423-1427.

8. Terry MA, Straiko MD, Goshe JM, Li JY, Davis-Boozer D. Descemet's stripping automated endothelial keratoplasty: the tenuous relationship between donor thickness and postoperative vision. Ophthalmology. 2012;119(10):1988-1996.

9. Wacker K, Bourne WM, Patel SV. Effect of graft thickness on visual acuity after Descemet stripping endothelial keratoplasty: a systematic review and meta-analysis. Am J Ophthalmol. 2016;163:18-28.

10. Acar BT, Akdemir MO, Acar S. Visual acuity and endothelial cell density with respect to the graft thickness in Descemet's stripping automated endothelial keratoplasty: one year results. Int J Ophthalmol. 2014;7(6):974-679. 
11. Spadea L, Santamaria V, Vingolo EM, Cagini C, et al. Anterior corneal surface irregularity after Descemet-stripping endothelial keratoplasty for bullous keratopathy. Eur J Ophthalmol. 2016;26(3): 209-215.

12. Weissbart SB, Hammersmith KM, Ayres BD, et al. Influence of early Descemet stripping endothelial keratoplasty on visual outcomes in pseudophakic corneal edema. Am J Ophthalmol. 2016;172: 58-63.
13. Graffi S, Leon P, Mimouni M, et al. Anterior segment optical coherence tomography of post-Descemet stripping automated endothelial keratoplasty eyes to evaluate graft morphology and its association with visual outcome. Cornea. 2018;37(9):1087-1092.

14. Dickman MM, Cheng YY, Berendschot TT, van den Biggelaar FJ, Nuijts RM. Effects of graft thickness and asymmetry on visual gain and aberrations after Descemet stripping automated endothelial keratoplasty. JAMA Ophthalmol. 2013;131(6):737-744.

\section{Publish your work in this journal}

The International Medical Case Reports Journal is an international, peer-reviewed open-access journal publishing original case reports from all medical specialties. Previously unpublished medical posters are also accepted relating to any area of clinical or preclinical science. Submissions should not normally exceed 2,000 words or
4 published pages including figures, diagrams and references. The manuscript management system is completely online and includes a very quick and fair peer-review system, which is all easy to use. Visit http://www.dovepress.com/testimonials.php to read real quotes from published authors.

Submit your manuscript here: https://www.dovepress.com/international-medical-case-reports-journal-journal 